\title{
Perioperative handover using ISBAR at two sites: A quality improvement project
}

Follow this and additional works at: https://www.journal.acorn.org.au/jpn

Part of the Health Services Administration Commons, Health Services Research Commons, Perioperative, Operating Room and Surgical Nursing Commons, and the Surgery Commons

(c) $\underset{\mathrm{EY}}{(\mathbf{3}}$

This work is licensed under a Creative Commons Attribution 4.0 License.

\section{Recommended Citation}

Kitney, Patricia (2018) "Perioperative handover using ISBAR at two sites: A quality improvement project," Journal of Perioperative Nursing: Vol. 31 : Iss. 4 , Article 3.

Available at: https://doi.org/10.26550/2209-1092.1031

https://www.journal.acorn.org.au/jpn/vol31/iss4/3

This Article is brought to you for free and open access by Journal of Perioperative Nursing. It has been accepted for inclusion in Journal of Perioperative Nursing by an authorized editor of Journal of Perioperative Nursing. 


\section{Perioperative handover using ISBAR at two sites: A quality improvement project}

\section{Cover Page Footnote}

Ms Patricia Kitney GradCertPeriop, GradCert LdrshipEdTrng, MEd (Research), BAppSc-Nsg, DAppSc-Nsg Ed, CertIVTAE, RN Clinical Nurse Educator in Perioperative Services, Western Health Dr David Bramley MBBS MPH GDip HIth\&MedLaw FANZCA Specialist Anaesthetist and Deputy Director, Department of Anaesthesia and Pain Medicine, Western Health Dr Raymond Tam MBBS FANZCA, Specialist Anaesthetist, Department of Anaesthesia and Pain Management Dr Koen Simons, Centre for Epidemiology and Biostatistics, Melbourne School of Population and Global Health, The University of Melbourne Western Centre for Health, Research and Education, Western Health 


\section{Authors \\ Patricia Kitney \\ MEd (Research), GradCertPeriop, GradCert LdrshipEdTrng, BAppSc-Nsg, RN \\ Clinical Nurse Educator in Perioperative Services, Western Health \\ Perioperative handover using ISBAR at two sites: A quality improvement project}

Dr David Bramley

MBBS, MPH, GDip Hlth\&MedLaw, FANZCA Specialist Anaesthetist and Deputy

Director, Department of Anaesthesia and Pain Medicine, Western Health

Dr Raymond Tam

MBBS, FANZCA

Specialist Anaesthetist, Department of Anaesthesia and Pain Management

Dr Koen Simons

Centre for Epidemiology and Biostatistics, Melbourne School of Population and Global Health, The University of Melbourne Western Centre for Health, Research and Education, Western Health

\section{Corresponding Author}

Patricia Kitney patricia.kitney@wh.org.au
Phase 2: Observation of the quality of handovers since inception of project including initial assessment of all other handovers points

\begin{abstract}
Background: The use of ISBAR handover principles assists in enabling the provision of best care to perioperative patients'. Reviews of post-operative handover research studies confirm the positive association between the quality of handovers and the decrease in adverse patient events ${ }^{2,3}$. Other reviews identify that globally handovers can be highly unpredictable and unreliable $e^{3-6}$. Therefore, the argument for standardised handovers to reduce the probability of adverse patient events in comparison to unstructured handovers, which have been shown to increase the chances of adverse patient events, is worth investigating.
\end{abstract}

Method: The method used was a multisite quasi-experimental design involving audits of perioperative handovers over a one week period in 2017. Using a pretest-posttest design, the use of ISBAR principles for all handover events during the perioperative journey was audited. The handovers studied included:

- ward nurse to holding bay nurse

- anaesthetist to Post Anaesthesia Care Unit (PACU) nurse

- scout nurse to PACU nurse

- PACU nurse to ward nurse.

The audits were conducted across two study sites over a one week period. The audit data were collected by study site clinical nurse educators and PACU nurses. Audit tools based on a prior perioperative handover investigation at Western Health (phase 1) were used.

Local resources were used to develop video vignettes depicting an ideal ISBAR handover for each of the handover points. These have been made available on WeLearn (organisation online training) as an education tool. In addition, cue cards were developed to prompt and guide practitioners to use ISBAR principles for handover

Results: Interventions to improve perioperative handovers were made and subsequent audit of handovers have commenced. This phase of the study provides comparisons of handovers between anaesthetists and PACU nurses over three different time periods. Some qualitative comparisons have been made. Additionally, this study collected baseline data for all other handover points of care.

Implications for practice: The results from this study suggest an augmented education program over time produced statistically significant $(p<0.001)$ results for compliance with ISBAR principles for handover from anaesthetist to PACU nurse. The results of the audits from the other perioperative handover points provided baseline data that will be used for comparison with further audit data for these handover points.

Keywords: handover, anaesthetist, post-anaesthetic care, post-anaesthetic nurse, holding bay nurse, scout nurse, ward nurse 


\section{Background}

ISBAR is a structured approach to communication between health care providers. ISBAR stands for introduction/identification, Situation, Background, Assessment and Request/Recommendation? Clinical handovers occur every day in a multitude of ways in many health care settings such as acute care, aged care, maternity, paediatrics and surgical ${ }^{4,6}$. Poor or absent clinical handovers can have extremely serious consequences. Clinical handover aims to ensure the structured, accurate and timely transfer of information, responsibility and accountability?

In the perioperative environment surgeons, scrub nurses, anaesthetists, anaesthetic nurses and scout nurses are all involved in the care of the patient during a surgical procedure ${ }^{\text {. }}$ Each team member is accountable for the information they transfer from one part of the patient journey to the next.

The introduction of ISBAR handover principles at a large multi-site metropolitan health service in Melbourne, Victoria, was undertaken to provide a standardised organisation-wide approach?. The introduction of ISBAR handover principles identified issues of noncompliance in the perioperative setting resulting in the development of a quality improvement project to improve adherence to the principles.

Phase one of the project focused on handovers from anaesthetists to PACU nurses across two campuses of the study site in 20152. Pre- and post-intervention audit data revealed that education augmented with ISBAR posters improved compliance with ISBAR principles at one site but decreased compliance at the other.

This paper will focus on phase two of the project in which further audits of the handovers from anaesthetists to PACU nurses and baseline audits at all other points of transfer of care of the perioperative patient were conducted in March 2017.

Phase three of the study will be the final stage of the study. In this, a second and third analysis of the ISBAR handovers from ward nurse to holding bay nurse, scout nurse to PACU nurse and PACU nurse to ward Nurse will be audited and analysed to determine extent of compliance with ISBAR principles for these handover points over time.

\section{Aim}

The aim of the current project is to assess the effectiveness of long-term strategies to improve compliance with ISBAR handover principles in a previously studied cohort. A secondary goal was to establish baseline data on other points of handover during clinical care. This project has also provided an opportunity for evaluation and monitoring of clinical handover in the perioperative setting of two campuses of a major metropolitan health service.

\section{Methods}

\section{Design}

The method used was a multisite quasi-experimental design involving audits of perioperative handovers over a one week period in 2017. A pretest-posttest cohort design using audit tools to measure compliance before and after quality improvement interventions was used. The audit tool was reviewed and adapted based on the dataset required at each point in care. The audit tool for the anaesthetist to PACU nurses handover was not changed to ensure minimisation of variables to mirror the previous audits.

\section{Sample}

A convenience sample of anaesthetists and holding bay, scout, PACU and ward nurses were observed over a one-week period in two perioperative units from two participating hospitals within the same health service. Handovers were performed by anaesthetists and ward, scout and PACU nurses. These were included in the audit. There was insufficient data in the literature to guide detailed sample size calculations for comparison of before and after compliance with the ISBAR handover tool in PACU. A minimum of 50 audits were completed at each point of care.

\section{Table 1: Sample sizes}

\begin{tabular}{|c|l|c|}
$\begin{array}{c}\text { Sample } \\
\text { site }\end{array}$ & Handover point & $\begin{array}{c}\text { Sample } \\
\text { size }\end{array}$ \\
\hline 1 & holding bay & 51 \\
\hline 1 & scout to PACU & 50 \\
\hline 1 & PACU to ward/DPU & 51 \\
\hline 1 & anaesthetist to PACU & 50 \\
\hline 2 & holding bay & 50 \\
\hline 2 & scout to PACU & 56 \\
\hline 2 & PACU to ward/DPU & 50 \\
\hline 2 & anaesthetist to PACU & 55 \\
\hline
\end{tabular}

\section{Intervention}

Training and education, such as simulation scenarios, inservices and as part of orientation information, was provided as part of scheduled anaesthetist training sessions to the anaesthetists in phase one (between audit one and two) of the project. No training was provided in phase two.

At the completion of the baseline audit for holding bay, scout and PACU nurses, specific cue cards were developed and placed in each holding bay cubicle, theatre and PACU cubicle (see Appendix 1). Further explicit vignettes were also 
developed that depicted both poor and ideal ISBAR handovers at each of these points of care. These were added to the original vignette set depicting poor and ideal anaesthetist to PACU nurses ISBAR handover to provide a whole suite of educational strategies that catered for each point of care.

\section{Tool}

The original audit tool was used to audit handover from the anaesthetist to PACU nurse. The anaesthetist to PACU nurse audit tool was designed to encompass guidelines from the Australian and New Zealand College of Anaesthetists (ANZCA) and the health care organisation.

However, there are no equivalent guidelines in the literature to inform the development of these audit tools for the other perioperative handover points. Therefore, the original tool was modified to suit the particular needs of each point of care and health professional (Appendix 2). The questions in the

Table 2: Audit tool items for anaesthetist handover to PACU nurse

\begin{tabular}{|c|c|}
\hline Identification & Patient name \\
\hline \multirow[t]{2}{*}{ Situation } & Procedure \\
\hline & Anaesthetic type \\
\hline \multirow[t]{3}{*}{ Background } & Allergies \\
\hline & Comorbidities \\
\hline & Communication difficulties (including NESB) \\
\hline \multirow{5}{*}{$\begin{array}{l}\text { Assessment + } \\
\text { actions }\end{array}$} & Intra-operative issues: surgery and anaesthesia \\
\hline & $\begin{array}{l}\text { Cardiovascular: observations, acceptable limits, therapy } \\
\text { (including IV fluids/flush and interventions) }\end{array}$ \\
\hline & $\begin{array}{l}\text { Respiratory: observations, acceptable limits, therapy } \\
\text { (includes } \mathrm{O}^{2} \text { ) }\end{array}$ \\
\hline & Analgaesia: interventions to date, ongoing therapy \\
\hline & $\begin{array}{l}\text { Additional needs: anti-emetics, x-ray, biochemistry/ } \\
\text { haematology/BSL }\end{array}$ \\
\hline \multirow{2}{*}{$\begin{array}{l}\text { Responsibility + } \\
\text { referral }\end{array}$} & Name and contact details \\
\hline & ICU/HDU/ward/discharge home \\
\hline
\end{tabular}

\section{Ethics}

what was common practice at these points of care. As with the previous phase of this project, to assist with face validity and content validity the tool was disseminated to expert clinicians and minor modifications were made. The tool was then piloted before the audits were able to take place to ensure content validity and interpretation of audit requirements.

\section{Data collection}

The anaesthetist to PACU nurse audit tool was completed by PACU nursing staff at the two study sites during the clinical handover by the anaesthetist once the patient had been connected to monitoring equipment and the patient was deemed stable by the PACU nurse.

The audits at the other points of care were conducted by the clinical nurse educators. Completed audits were placed into secure boxes which were collected at the end of the one-week period by the project team leader.

Quality assurance was reviewed by the study site Low Risk Research and Ethics Panel for the first phase of the project. Amended approval (low risk human research QA Reference Number: QA2014.94) was granted on 8 March 2016 for the remaining two phases of the project. Formal consent was not sought from staff; however, all staff were made aware that ISBAR audits were being undertaken at the regular staff morning meetings and verbally before handover commenced. Participants were non-identifiable as no identifying demographics were recorded.

\section{Outcome measures}

The outcome measures were differences in compliance between pre- and post-audit for all audit tool items i.e. for the handover between anaesthetists and PACU nurses. For the other handover points there was no outcome measure as it was collection of baseline data.

\section{Data analysis}

To compare overall compliance rates between the three anaesthetist to PACU nurse audits and two hospitals, the itemwise compliance rates were pooled for handover point over the 13 shared questions of the audit tool and fit a logistic regression model to estimate the effect of audit-number, site and the interaction between audit number and site. To account for possible difference between itemwise compliance rates, the model was refitted including a random effect for question type.

Differences between handover point and item-specific compliance rates were visually assessed by graphing the estimated rates and exact confidence intervals, using data from the first audit.

All available data from audit forms that were partially completed were 
retained with an indication of compliance or non-compliance and blanks ignored. Such blanks can occur, for example, if the auditor has to respond to an emergency. Hence, interpreting blanks as non-compliant is likely to result in negative bias.

All analyses were performed using the R 3.4.2 tool and random effects were fitted using the $\mathrm{Ime}^{4}$ package.

The fitted overall itemwise compliance rates are shown in Figure 1. Compliance was higher at site 1 at all times (OR 1.8 [1.5; 2.1]). Both hospitals showed improved compliance over the three audits (OR 1.3 [1.05; 1.5], respectively 3.3 [2.6; 4.1]). As both main effects are significant, in addition a fitted model with interaction was included, indicating that site 1 had the largest amount of improvement between audits three and audit one.

To further investigate potential differences between handover points and item-specific compliance, the item-specific rates for the first audit were graphed (see Figure 2). As there was only limited data, confidence intervals were not corrected for multiple testing. Clearly, the majority of pairwise comparisons within each question-setting combination are not statistically significant, but overall there is an indication of difference between the groups, with scout nurses having lower compliance rates.

\section{Discussion}

The major findings from this phase of the project indicate that there was a marked overall improvement in compliance with all the items of the ISBAR handover from anaesthetists to PACU nurses (Figure 1). The changes in handover practice in this group are quite apparent and statistically significant. The results also indicated that one hospital (site 1) did better than the other in improved compliance with ISBAR handover practices between anaesthetists to PACU nurses. This would indicate that education strategies and increased awareness of the requirements for handover intensified compliance over time as there was a demonstrable change between audit one and audit three.

Figure 2 provides the baseline data collected for the first audit at all other points of care where handover is provided in the perioperative journey. At this stage there are no trends between hospitals. Holding bay and PACU to ward handover sites had the best initial compliance with the items on the audits, whereas scout to PACU nurse results are

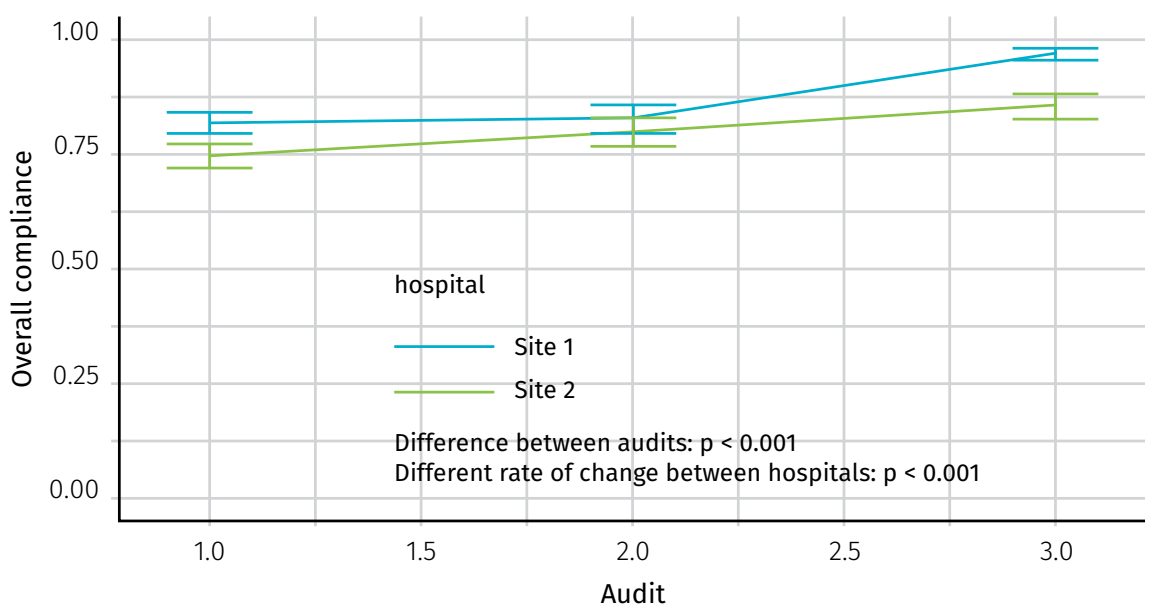

Figure 1: Overall compliance for anaesthetists to PACU nurse for the three audits more disparate, which fits in with scout nurses, historically, not always providing uniform or structured handovers to PACU nurses.

\section{Findings in context of the literature}

The literature in this area has identified those areas where teamwork is a critical factor for keeping people alive (for example aviation and Formula 1 car racing), using structured strategies including education, checklists and cue cards to ensure all steps are covered provides better outcomes. When these strategies are used in the perioperative setting it results in a structured approach to perioperative handovers leading to better patient outcomes ${ }^{5,6,9}$. This study confirms that targeted education strategies (simulations, in-services, cue cards) that are delivered to a specific team of perioperative health professionals i.e. anaesthetists increase compliance to ISBAR handover principles.

\section{Strengths and limitations}

The major strength of this study was that it was undertaken in a practice environment in two large teaching hospitals within the one health service. In saying this, factors influencing ISBAR compliance, such as PACU leadership and management culture, were not objectively measured. This was a pretestposttest audit design and thus findings should not be generalised to other PACU contexts.

The strength of this study was that no further education interventions were in place before the audits which indicates that the initial strategies have had a lasting effect. This also indicates that despite changes in anaesthetist personnel, the communication of the handover expectations at orientation increased compliance. 

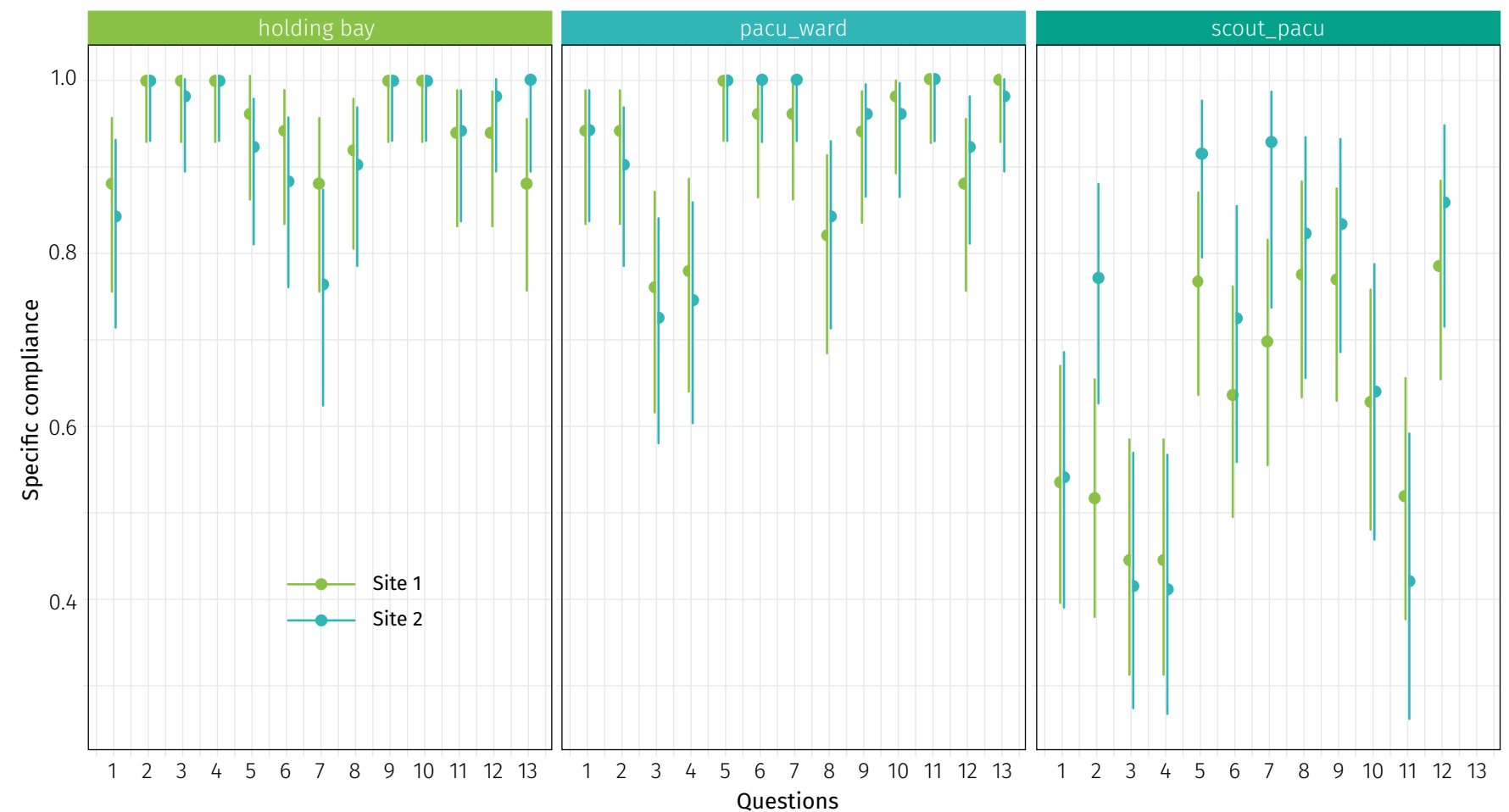

Figure 2: Initial (baseline) audit results for all other handover points

No other factors, such as handover governance, policy or systems, were assessed as part of this project.

The other limitation is that the patient and/or carer was not involved due to the nature of the audit tool and aspects of the environment such as the state of consciousness of the patient and being in a restricted access area. In future studies the patient could be involved in the holding bay handover point. Audit design for future study would need adaption to incorporate patient involvement in the handover event.

The audits were performed so as to ensure anonymity. This limits options for statistical analysis and foregoes estimating and taking into account factors specific to particular staff members even though it is possible or likely that the same person has taken part in the same audit multiple times.

Furthermore, this study did not take into account correlations between non-compliances. Indeed, when one question was not correctly addressed it frequently occurred that one or more other questions were also not correctly addressed; however, there was no clear pattern of simultaneous non-compliance on multiple patterns. As such, the data is not sufficiently rich to warrant a multivariate model. Generally, the use of composite endpoints such as a score out of 13 or a binary assessment of overall compliance would be recommended. However, such an approach is restricted to data that is complete or requires some form of imputation. For example, if twelve items are recorded as positive and one is not recorded, the entire record would have to be discarded or a score of $12 / 13$ or $13 / 13$ would need to be assigned.

Finally, while no additional training was undertaken, this study measured long-term compliance without structured interventions for anaesthetists and PACU nurses and collected baseline data for all other points of care. Participants were aware of the audit and this in itself may have had an influence on immediate compliance by reminding the participants of the training.

\section{Conclusion}

This study shows that compliance with using ISBAR principles in handover between anaesthetist and PACU nursing staff has continued to improve over time. Baseline data from all handover points indicated that there was good compliance in two areas whereas handover from scout nurse to PACU nurse was below the standard expected.

Reauditing of the handover points from ward nurse to holding bay, scout nurse to PACU nurse, and PACU nurse to ward nurse will be undertaken to examine the effect of further specific educational investigations targeting these handover points. 


\section{References}

1. Western Health. Clinical handover. Policy code P-CC5.2, 2014. Footscray: Western Health; 2014.

2. Kitney P, Tam R, Bennett P, Buttigieg D, Bramley D, Wang W. Handover between anaesthetists and post-anaesthetic care unit nursing staff using ISBAR principles: A quality improvement study. Journal of Perioperative Nursing 2016;29(1):30-35.

3. Segall N, Bonifacio A, Schreder R, Barbeito $A$, Rogers D, Thornlow D et al. Can we make post-operative handovers safer? A systematic review of the literature. Anesth Analg 2012;115(1):102-115.

4. Botti M, Bucknall T, Johnstone M, Redley B, Evans S, Jeffcott S. Examining communication and team performance during clinical handover in a complex environment: The private sector postanaesthetic care unit. Med J Aust 2009;190(11):S157-160.

5. Boat A, Spaeth J. Handoff checklists improve the reliability of patient handoffs in the operating room and postanaesthesia care unit. Paediatr Anaesth 2013;23(27):647-654.
6. Catchpole K, Pigott N, Elliott M, Mc Quillan A, Mac Donald C, Goldman A. Patient handover from surgery to intensive care: Using Formula 1 pit-stop and aviation models to improve safety and quality. Paediatr Anaesth 2007;17(5):470-478.

7. Australian Commission on Safety and Quality in Health Care. OSSIE guide to clinical handover improvement [Internet]. Sydney: ACSQHC; 2010 [cited 2017 January 10]. Available from: www.safetyandquality.gov. au/wp-content/uploads/2012/01/ossie.pdf.

8. Anumakonda V, Doijode S, Bhaskaran S. A prospective audit of multidisciplinary handover (MDHO) of responsibility for patients in the post-anaesthetic care unit in a District General Hospital (DGH): Patient safety perceptive. Eur J Anaesthesiol 2011;28(Supp48):215.

9. Wacker J, Kolbe M. The challenge of learning from perioperative patient harm. Trends in Anaesthesia and Critical Care 2016;(7-8):5-10.

\section{Appendix 1a: \\ ISBAR perioperative handover flow chart}

\begin{tabular}{|c|c|}
\hline \multicolumn{2}{|l|}{ Holding bay } \\
\hline $\begin{array}{l}\text { Ward/DPU/ED } \\
\text { nurse and patient } \\
\text { with holding bay } \\
\text { nurse }\end{array}$ & $\begin{array}{l}\text { ISBAR cue card } 1 \\
\text { Passport to } \\
\text { surgery AD } 250\end{array}$ \\
\hline \multicolumn{2}{|l|}{ Intra-operatively } \\
\hline $\begin{array}{l}\text { Team time out } \\
\text { Multidisciplinary }\end{array}$ & $\begin{array}{l}\text { Passport to } \\
\text { surgery AD } 250\end{array}$ \\
\hline \multicolumn{2}{|l|}{ PACU } \\
\hline $\begin{array}{l}\text { Anaesthetist to } \\
\text { PACU nurse } \\
\text { Scrub/scout nurse } \\
\text { to PACU nurse } \\
\text { PACU nurse to } \\
\text { ward/DPU nurse }\end{array}$ & $\begin{array}{l}\text { ISBAR cue card } 2 \\
\text { ISBAR cue card } 3 \\
\text { ISBAR cue card } 4\end{array}$ \\
\hline
\end{tabular}




\section{Appendix 1b: Sample cue cards and handover flow chart}

\section{ISBAR cue card 1}

\section{ISBAR prompts for ward/DPU nurse handover to holding bay nurse}

\begin{tabular}{|c|c|c|c|c|}
\hline IDENTIFY & \multicolumn{4}{|c|}{$\begin{array}{l}\text { Handing over nurse identifies self. } \\
\text { Identify the patient with three key identifiers: Patient (or designated other if unable) must state: } \\
\text { - first and last name } \\
\text { - date of birth } \\
\text { - UR number. }\end{array}$} \\
\hline SITUATION & \multicolumn{4}{|c|}{$\begin{array}{l}\text { Ask patient 'What procedure will be performed?' (Check against theatre list.) } \\
\text { Check consent is correct with theatre list. }\end{array}$} \\
\hline BACKGROUND & \multicolumn{4}{|c|}{$\begin{array}{l}\text { What is the background/reason for surgery? } \\
\text { Any other medical or surgical concerns/history. }\end{array}$} \\
\hline ASSESSMENT & $\begin{array}{l}\text { Follow ‘Passport tc } \\
\text { Should clearly sta } \\
\text { Examples of releva } \\
\text { - cognition } \\
\text { - falls } \\
\text { - pressure injury } \\
\text { - continence } \\
\text { - nutrition }\end{array}$ & $\begin{array}{l}\text { ery AD250' } \\
\text { sther the patient has been ic } \\
\text { sessment and risks: } \\
\text { - aggression/violence } \\
\text { - most recent vital signs } \\
\text { - trends in vital signs } \\
\text { - oxygen therapy } \\
\text { - medication i.e. cytotoxic }\end{array}$ & $\begin{array}{l}\text { d as being at risk. } \\
\text { - pain } \\
\text { - bleeding } \\
\text { - weight } \\
\text { - wound status } \\
\text { - urine output }\end{array}$ & $\begin{array}{l}\text { - carer concern } \\
\text { - communication } \\
\text { - IV cannula site/therapy } \\
\text { - transmission precautions }\end{array}$ \\
\hline $\begin{array}{l}\text { REQUEST/ } \\
\text { REFERRAL }\end{array}$ & \multicolumn{4}{|c|}{$\begin{array}{l}\text { All required patient documentation present. } \\
\text { Patient readiness for surgery. }\end{array}$} \\
\hline
\end{tabular}

\section{ISBAR cue card 2}

\section{ISBAR prompts for scout nurse handover to PACU nurse}

\begin{tabular}{|c|c|c|c|c|}
\hline IDENTIFY & \multicolumn{4}{|c|}{$\begin{array}{l}\text { Handing over nurse identifies self. } \\
\text { Identify the patient with three key identifiers: Patient (or designated other if unable) must state: } \\
\text { - first and last name } \\
\text { - date of birth } \\
\text { - UR number. }\end{array}$} \\
\hline SITUATION & \multicolumn{4}{|c|}{ What procedure was performed. } \\
\hline BACKGROUND & \multicolumn{4}{|c|}{ Any surgical/intra-operative concerns. } \\
\hline ASSESSMENT & $\begin{array}{l}\text { Dressings } \\
\text { Drains } \\
\text { Specimens } \\
\text { Examples of relev } \\
\text { - cognition } \\
\text { - falls } \\
\text { - pressure injury } \\
\text { - continence } \\
\text { - nutrition }\end{array}$ & $\begin{array}{l}\text { sment and risks: } \\
\text { - aggression/violence } \\
\text { - most recent vital signs } \\
\text { - trends in vital signs } \\
\text { - oxygen therapy } \\
\text { - medication i.e. cytotoxic }\end{array}$ & $\begin{array}{l}\text { - pain } \\
\text { - bleeding } \\
\text { - weight } \\
\text { - wound status } \\
\text { - urine output }\end{array}$ & $\begin{array}{l}\text { - carer concern } \\
\text { - communication } \\
\text { - IV cannula site/therapy } \\
\text { - transmission precautions }\end{array}$ \\
\hline $\begin{array}{l}\text { REQUEST/ } \\
\text { REFERRAL }\end{array}$ & \multicolumn{4}{|l|}{ Transfer to PACU. } \\
\hline
\end{tabular}




\section{Appendix 2: Modified handover audit tools for phase two of project for handover points excluding anaesthetists to PACU nurses.}

\begin{tabular}{|c|c|c|c|c|}
\hline \multicolumn{3}{|c|}{ HANDOVER AUDIT IN HOLDING BAY NURSE } & Yes & No \\
\hline \multirow{4}{*}{ I } & \multirow{4}{*}{ IDENTIFICATION } & Staff & & \\
\hline & & Patient name (first and last name) & & \\
\hline & & Patient date of birth & & \\
\hline & & Patient UR number & & \\
\hline \multirow{3}{*}{ S } & \multirow{3}{*}{ SITUATION } & Why is the patient being transferred to holding bay? & & \\
\hline & & Ask patient 'What procedure will be performed?' (check against theatre list) & & \\
\hline & & Check consent is correct with theatre list & & \\
\hline \multirow{2}{*}{ B } & \multirow{2}{*}{ BACKGROUND } & What is the background/reason for surgery & & \\
\hline & & Any other medical or surgical concerns/history & & \\
\hline \multirow{2}{*}{ A } & \multirow{2}{*}{ ASSESSMENT+ ACTIONS } & Follow Passport to surgery AD 250 & & \\
\hline & & Were any potential patient 'at risk' factors discussed/identified & & \\
\hline \multirow{3}{*}{$\mathrm{R}$} & \multirow{2}{*}{ RESPONSIBILITY+ RFERRAL } & All required patient documentation present & & \\
\hline & & Patient readiness for surgery & & \\
\hline & & Total Score $=13$ & & \\
\hline
\end{tabular}

\begin{tabular}{|c|c|c|c|c|}
\hline \multicolumn{3}{|c|}{ HANDOVER AUDIT SCOUT TO PACU NURSE } & Yes & No \\
\hline \multirow{4}{*}{ I } & \multirow{4}{*}{ IDENTIFICATION } & Self & & \\
\hline & & Patient name (first and last name) & & \\
\hline & & Patient date of birth & & \\
\hline & & Patient UR number & & \\
\hline $\mathrm{S}$ & SITUATION & What procedure (s) was performed & & \\
\hline B & BACKGROUND & Any surgical/intra-operative concerns & & \\
\hline \multirow{5}{*}{ A } & \multirow{2}{*}{ ASSESSMENT+ ACTIONS } & Dressings & & \\
\hline & & Drains & & \\
\hline & & Local & & \\
\hline & & Specimens & & \\
\hline & & Is patient identified as 'at risk'? & & \\
\hline \multirow[t]{2}{*}{$\mathrm{R}$} & RESPONSIBILITY+ RFERRAL & All required patient documentation present & & \\
\hline & & Total Score $=12$ & & \\
\hline
\end{tabular}

\begin{tabular}{|c|c|c|c|c|}
\hline \multicolumn{3}{|c|}{ HANDOVER AUDIT PACU TO WARD/DPU NURSE } & Yes & No \\
\hline \multirow{4}{*}{ I } & \multirow{4}{*}{ IDENTIFICATION } & Self & & \\
\hline & & Patient name (first and last name) & & \\
\hline & & Patient date of birth & & \\
\hline & & Patient UR number & & \\
\hline \multirow{3}{*}{$\mathrm{S}$} & \multirow{3}{*}{ SITUATION } & What procedure (s) was performed & & \\
\hline & & What type of anaesthetic the patient had & & \\
\hline & & Drugs given intra-operatively & & \\
\hline \multirow{3}{*}{ B } & \multirow{3}{*}{ BACKGROUND } & What was the background/reason for surgery & & \\
\hline & & Any relevant history? & & \\
\hline & & Any intraoperative/medical concerns & & \\
\hline \multirow{2}{*}{ A } & \multirow{2}{*}{ ASSESSMENT+ ACTIONS } & Follows Operation report and Post-operative orders AD 253 & & \\
\hline & & Is patient identified as 'at risk'? & & \\
\hline \multirow[t]{2}{*}{$\mathrm{R}$} & RESPONSIBILITY+ RFERRAL & Discharge summary completed and documented & & \\
\hline & & Total Score $=13$ & & \\
\hline
\end{tabular}

